\title{
Energy Management System Designed for Residential Grid connected Micro Grid
}

\author{
N.Pooja ${ }^{a}$, D.Krishna ${ }^{b}$ \\ ${ }^{a}$ M.Tech student Anurag Group of institutions, Hyderabad,India poojanandhikonda@gmail.com \\ ${ }^{\mathbf{b}}$ Assistant Professor,EEE Department Anurag Group of institutions Hyderabad,India krishnaeee@cvsr.ac.in
}

Article History: Received: 10 November 2020; Revised 12 January 2021 Accepted: 27 January 2021; Published online: 5 April 2021

\begin{abstract}
This paper presents an energy management system supported by PI Controller for a residential grid connected micro grid with renewable hybrid generation (wind and photo voltaic) and battery system. Modeling hybrid system includes non conventional energy sources given at sporadic supply conditions and dynamic energy demand, and to make conceptual energy storage with the help of battery system. Designing an appropriate scheme that dynamically changes modes of renewable integrated system based on the availability of RES power and changes in load. Wind,PV are the primary power supply of the system; battery is going to be act as a substitute.The PI controller is developed and carried out for the aimed hybrid(Wind and PV) energy system to integrate the non conventional energy sources to the serviceability either to grid or to Residential loads.main objective is improvement of transients during switching periods by using an efficient PI controller.maximum power point tracking is also other objective is energy management system designed for the residential grid connected Micro Grid. Simulations are carried out on the proposed Hybrid energy system using MATLAB/ SIMULINK.
\end{abstract}

Keywords: Energy management, micro grid, Non Conventional Energy sources.

\section{Introduction}

The inflection towards non conventional sources of energy generation is led by uncertainty cause to be due to fast reduction of fossil fuels [1]. A Micro Grid is a small power system consists of local generation from the alternate Energy sources such as wind ,PV,etc it can function Independently or in accordance with the centralised power Grid. [2],[3]. Micro Grid can act individually or can be mingled with the centralised Grid either on transmission level or Distribution level depends on the scheme of the system. For a residential Micro Grid, the system is integrated on the low voltage (LV) distribution level network where the power generation mediums are referred to as distributed energy resources (DERs). General examples of DERs include small scale wind turbines, photo voltaic (PV)systems, micro turbines, diesel-generators, etc. Conventional micro-grids are affiliated in a topology that enables the system to be Grid connected or to be disconnected from the main grid (island-mode) [4]. The Grid connected topology is the most common and simplest to implement, since the energy balance between generated energy and consumed energy is maintained. However, in case of the Distributed Energy sources connected to the micro-grid generates excess amount of energy, it is fed to the centralised Grid to maintain the energy balance, [5]. In Grid Disconnected Mode it is not that simple as there is no additional loads to which excessive energy can be fed back to maintain the energy balance. This interference is overcome by a large battery bank,it acts as a buffer between the DER and the loads. The PV modules are used only to charge the batteries and thereafter the batteries supply the loads. With the rising electricity prices,most residential electricity consumers are considering grid-tied micro-grid systems consisting of small scale non conventional energy resources such as wind mills and photo voltaic systems. According to [6] and [7], the fulfillment of residential grid-tied micro-grids can forcefully improve reliability and decrease the monthly electricity bill whilst reducing pressure off the grid. Micro grid's are outlined as low voltage systems comprising loads,Distributed Generation (DG) units Colleague in storage devices with an Energy Management System linked and connect to the grid at a Common Coupling point(PCC)[8]; so, The power revolved with the grid is locally controlled by the Energy Management System(EMS) . non conventional energy resources will become an increasingly vital part of Power Generation because the savings of conventional energy sources get closer to exhaustion. Among all available undepletable energy technologies, wind and solar power sources are the first off promising choices, as they're ubiquitous, freely obtainable, and biodegradable. Though these technologies are rising in several aspects, the drawbacks related to them, such as their distinctive features and high capital cost, are the main impediment for their utilization.Hybrid(Wind \&PV) power system with Battery arrangement can increase system reliability, power availability, quality and operational efficiency.Different hybrid (PV and Wind)power systems with Maximum Power Point Tracking(MPPT) control have been relieved earlier [9]. They used individual DC/DC boost converter and buck-boost converter linked in coalition in the rectifier stage to practice the MPPT 
management for the Non Conventional energy sources. These systems have a problem that, due to the environmental factors dominating the Wind mill Generator, high frequency current Harmonics are placed into it.Boost converter and buck-boost converters are not attainable to take out these harmonics. So the system now here needs passive input filters to leave out of it, creating the system very substantial and costly [10]. The strategy based on the Energy Management System is complicated based on the application and its design. In [11] PN Sidharth et. al designed a hybrid inverter for domestic usage and it is controlled by Fuzzy PI to ensure the efficient performance

\section{System design and modeling:}

Fig.1. represents the Residential Grid connected Micro grid.Generated energy from the Photo voltaic generator is given to $\mathrm{DC} / \mathrm{DC}$ boost converter. The variable output voltage of the photo voltaic generator is regulated by mppt controller. The generated energy is first rectified and then regulated by a DC/DC buck converter. The DC bus collects the total power from the wind and photo voltaic system and uses it to supply the loads. Where, PPV is the PV power generated by Photo voltaic generator; PWT is the power generated by Wind turbine generator; PGEN is the power generated by the non conventional energy sources; PBAT is the power supplied by the battery; PGRID is the power available within the Micro grid; PLOAD is the power consumed by the Load; and PMGRID is the power delivered by the Main Grid. The power of each variable is considered positive when the power flows in contemplation of the arrow as shown in the figure(example: battery power is positive if the battery system supplies energy to the micro grid and negative if storage system absorbs energy from the micro grid). This section deals with the layout of the proposed system and illustration of the non depleatable energy resources present in the system. The non depleatable energy resources considered for the predetermined system are DFIG based wind generator and solar Photo Voltaic array and their designing aspects have been discussed later on.The Photo Voltaic array is carried out by MPPT Technique.

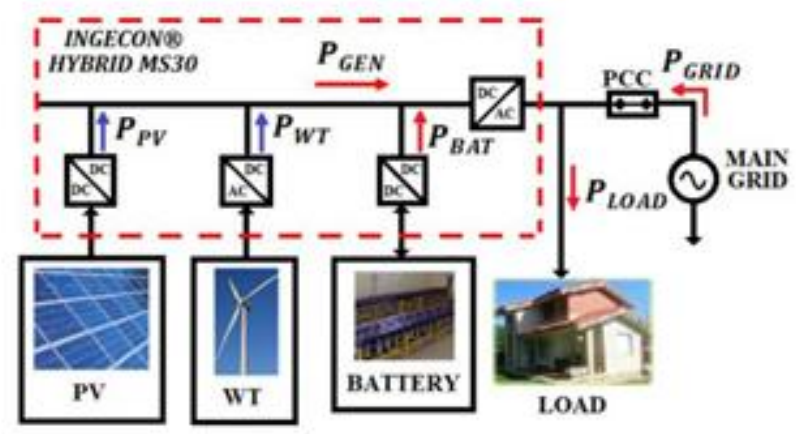

Fig. 1. Residential Grid connected Micro grid.

\section{Modelling of Sources}

The designing of doubly Fed Induction generator based wind mill and solar PV array is implemented by the preexisting conventional approach. The representation of the PV array has been done using one diode model of PV cell [11][12]. The DFIGenerator based wind mill has depicted electrically by using a fifth order rough cast of Induction Generator. The mechanical rough cast of the induction generator has been done by using one mass lumped model.

\section{Modelling of Converters}

The proposed system has three converters. A DC/DC boost converter is affiliated to solar/PV array to track MPP. The terminal voltage is regulated by continuous tracking of the operating point of the characteristic power versusvoltage curve of the module. An AC/DC/AC converter is used in the rotor circuit of the DFIG. This converter interconnects the rotor to the grid through loads.this is also used for reactive power control and to operate the Generator or Machine at maximum power point.

\section{A. Modelling of boost converter}

An averaged state space representation has been used to model the converter.The boost converter represented is used in employing the Perturbation and Observation based MPPT algorithm. 


\section{Modelling of Controllers}

A pitch control mechanism as well as a rotor side converter is designed for the DFIG.The pitch angle is computed continuously and is controlled as deserved by the system. The pitch angle is continuously recorded and compared with the reference value. The variation of the error signal is sent through a tuned Proportional Integral Controller to get a control signal as output. The rotor of the DFIG contains an AC/DC/AC converter through which it is coupled to the grid through loads. Since the machine is designed in dq reference frame, the scheming of controllers will become very easy. In this paper three controllers used: a.mppt controller b.Battery controller c.Inverter controller.

\section{A. mppt controller}

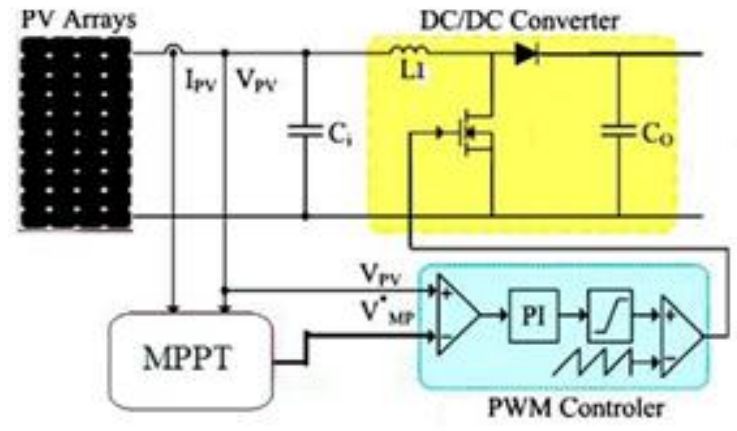

Fig. 2. MPPT Controller Design.

figure2 exemplifies the MPPT Controller design.Photo Voltaic connection to the DC/DC converter,DC/AC inverter and Grid. A DC/DC boost converter of PV system has two tasks : (a) changing the DC voltage level and (b) ensuring that the solar panel works at maximum power point (MPP). The MPPT algorithm determine the maximum power and the voltage at this point called Maximum Power Point.Reference voltage i.e V ref from the MPPT Controller and actual system voltage Vpv and current Ipv send through PV controller.it generates a pulse PV. The output voltage of the PV system is coordinated by a Proportional Integral Controller and hence control the output power by adjusting the duty cycle of the pulse width modulation (PWM).

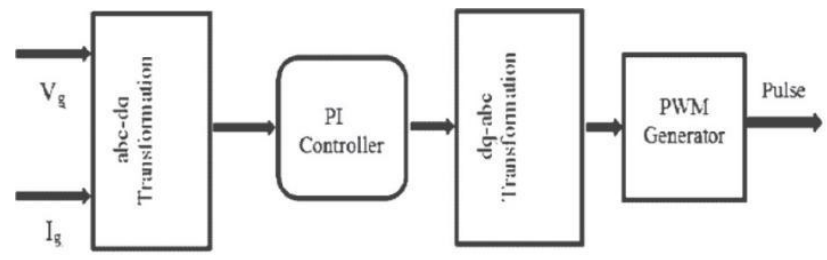

Fig. 3. Block diagram of inverter control.

\section{B. inverter controller}

figure 3 exemplifies the design of inverter control.As the generated voltage from non conventional energy sources that is from solar is DC, we need an inverter to alter or change DC voltage to AC voltage.before connecting it to grid and loads.where as Grid is a voltage source with infinite associability. inverter's output voltage and frequency should be same as that of grid frequency and voltage. The output of grid tied inverter can be controlled as a voltage source or current source and pulse width modulated (PWM)voltage source inverters (VSI) are most widely used. The three phase full bridge inverter topology is the most widely used configuration in three phase systems. The inverter selected for the present system is current controlled voltage source inverter. 


\section{C. battery controller}

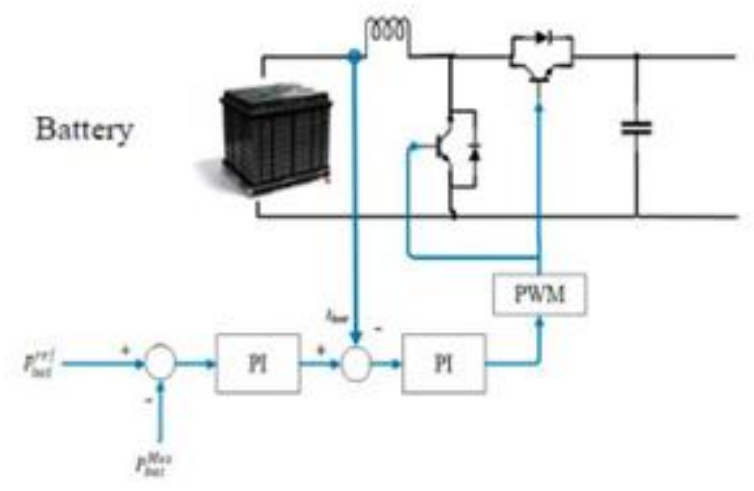

Fig. 4. Block diagram for battery control.

Figure 4 Exemplifies the design of Battery control. A bidi- rectional DC/DC converter is fashioned to control the charging or discharging power of the battery. This DC/DC converter consists of four switches with a Pulse Width Modulation control circuit. When switch S1 is OFF and switch S2 is ON,Converter works in buck mode. In this case, power is transferred from the DC bus to charge the battery.On the other hand, when switch $\mathrm{S} 1$ is ON and switch S2 is OFF, the converter works in boost mode and power is discharged from the battery and transferred to the DC bus.in the battery control two Proprtional Integral controllers used There are two control loops to control the charging or discharging power of the battery. The reference power, is regulated by a Proportional Integral (PI) controller.and second PI controller is used to regulate the current of the battery to protect the battery.

\section{Energy Management System}

Main objectives of Energy Management system is: 1)improvement of transients during switching periods.2.Maximum power point tracking.3.Energy management system for micro grid. With an objective of keeping the voltage value at the bus constant, the PI Controller will adjust the value so that the buck-boost converter changes its mode of operation to act in either buck mode or boost mode to reduce or increase the change in voltage value.The PI will anticipate the suitable value of the voltage considering the micro grids DC voltage over time and the reference value of DC voltage.main condition in the energy management system is load and grid are supplied through non conventional energy sources.and excess energy can be collected in storage system(battery) our first priority is our loads and then give to the Grid..battery energy can be used as backup.figure 10 represents the generated energy from the non conventional energy sources we are using.in this paper energy management is doing under two conditions: case1:when Grid is ON then Battery is OFF case2:when Grid is OFF then Battery is ON. Power generation in micro grid concept can work either in the group or independently and not connected in a larger network or utility grid. This concept provides power grids more reliability, high absorption of non conventional energy sources, self-healing, active load control, and improved efficiencies. A study from the International Energy Agency pointed out that a power system based on a large number of reliable small distributed generations can operate with the same reliability and a lower capacity margin than a system of equally reliable large generators. In smart grid scheme consumers can also act as electric producers to produce electric power and supply it to the network. There are very little micro grid systems linking an energy management system (EMS) to ensure that locally generate energy is consumed within the interconnected loads rather than feeding the excess energy into the grid. A well-designed EMS that exhibits a control system that can process information such as generation data, load data, consumption patterns, weather predictions and economic factors can be utilized to use the generated energy in the most efficient manner. to achieve goals related to energy efficiency improvements, supply and demand balance, emissions control, reduced operating costs, and utility maximization. The secondary objective :of the EMS is to ensure that as much as possible of the energy generated by the DER are consumed locally rather than fed into the grid. By achieving the secondary objective, the primary objective will be met.Conventional micro-grids are connected in a topology that enables the system to be grid- connected or to be disconnected from the grid (island-mode). The grid-tie topology is the most-common and very easy to apply,as the balance between generated and consumed energy is maintained. However, in the case where the DERs linked to the micro-grid generates excess energy, it is fed into the Main centralised grid to maintain the energy 
Balance.In Grid Disconnected Mode it is not that simple since there is no additional loads to which excessive energy can be fed to maintain the energy balance. This complication is overcome by using a large battery bank as a buffer between the DER and the loads. The Photo Voltaic modules are used only to charge the batteries and thereafter the batteries supply the load. Fig. 1illustrates the concept of DERs within the centralized grid. In this section, two possible operation modes are described: (1) Mode 1 :small-scale load: The Distributed Generators power is more than the demand in a specific period and less in other period of the day. So,that the micro grid may sell or purchase power to the Grid or sell or purchase from the Grid depends on the objectives of the operating scheme.The load in this mode consisted here of a two homes or set of homes and the demand. 2) Mode 2:large-scale load: The demand is constantly higher than the Distributed Generators power. thus, the shortage of the power demand can be bought from the centralised Grid and there will not be any power that can be sold to the grid. To apply this mode, it is assumed that another set of homes is coupled with the previous loads, which simply duplex the load demand. Case 1: This is where the demand is supplied by the utility grid only (Distributed Generators and Energy Storage Systems are not included). Case 2: In mode 1, The Micro Grid supplies the load with the demanded power and the excess amount of power will be stored in the battery until reaching the maximum capacity. our loads that is set homes are ultimate choice where as The utility grid is the final choice. In mode 2, storage system or battery and Distributed Generators provide the load with power and the power shortage is covered by the grid.

\section{Results}

A system has been implemented for the simulation studies of the hybrid micro-grid Model.the system designed to have a DGs units on the grid.
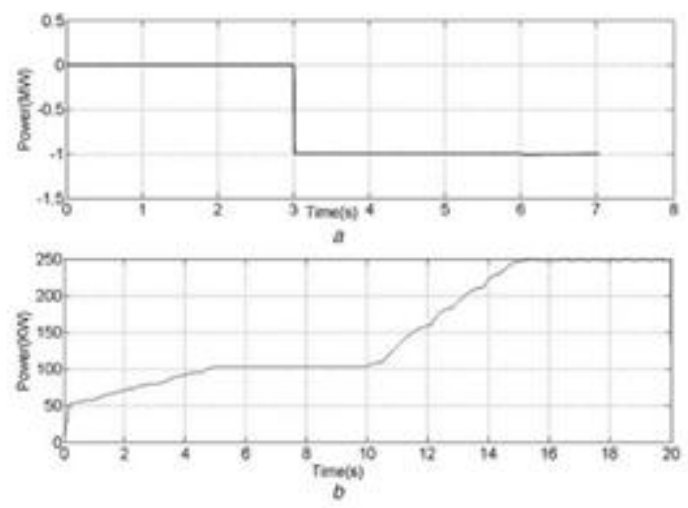

Fig. 5. power generation of renewable energy sources

figure 5 represents the variations in the irradiation level versus the output power.same figure also represents the output real power versus time of DFIG.

\section{A. Simulation Results Discussion:}

The proposed model is simulated in MATLAB/Simulation environment.final output results of the proposed micro grid with-out and with EMS are shown below figures.curves are arranged as grid power,battery power,load1power and load2power.

\section{B. without EMS}

without energy management powers are as shown in Fig6 to Fig9.total energy from Distributed Generation units consumed by the Main Grid as many loads connected to it.As this section deals without EMS without switching events energy is not managing properly.when we look through the battery power battery charging and discharging while grid is in ONcondition implies battery stored least energy. whereas load 1 and load 2 will not get any power or very less amount of power either loads will take large amount powers implies equipment will damage. 


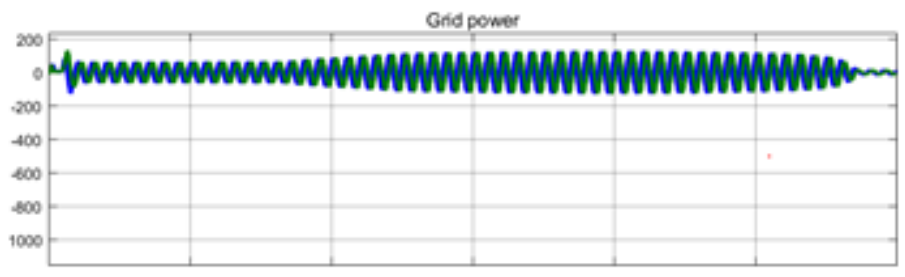

Fig. 6. Grid power

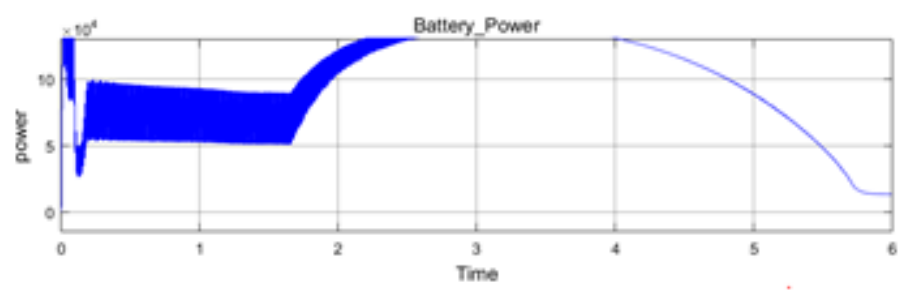

Fig. 7. Battery power

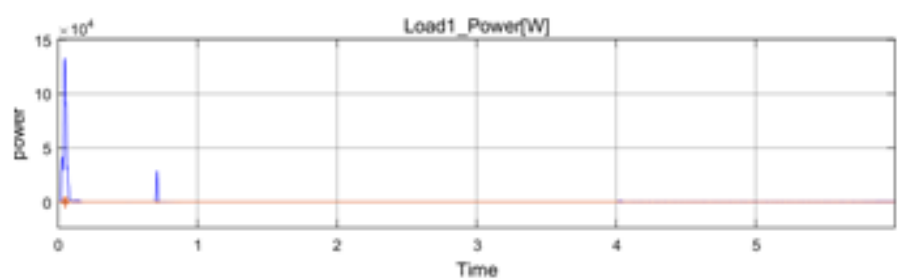

Fig. 8. Load1 power

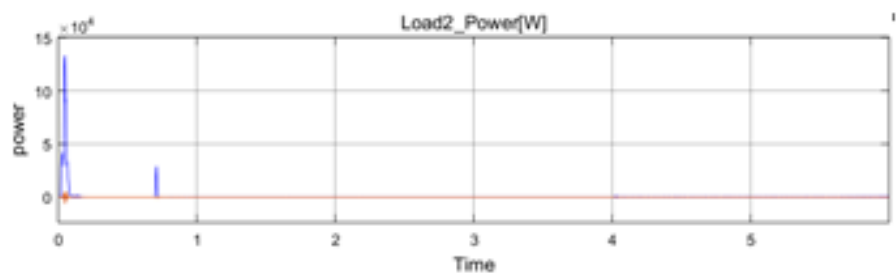

Fig. 9. Load2 power

\section{With EMS:}

With energy management system managing the powers efficiently by controller through switching events.whenever the Grid power is ON then Battery power is OFF.and the loads will be ON based on the requirement. Fig10 to fig13 represents the powers with EMS .In this grid power come to stable state in least time that is $0.03 \mathrm{sec}$ by using efficient controller.controller reduces the transient period.After $4 \mathrm{sec}$ Battery starts charging.At $1 \mathrm{sec}$ Load1 is $\mathrm{ON}$ and load1 transients reduced at $1.003 \mathrm{sec}$.again,at $4 \mathrm{sec}$ transients are occured and those are removed at $4.03 \mathrm{sec}$ load power1 come stable state while load 2 is switch $\mathrm{ON}$ at $3 \mathrm{sec}$ and transients occur at $4 \mathrm{sec}$ at $4.02 \mathrm{sec}$ comes to stable. 


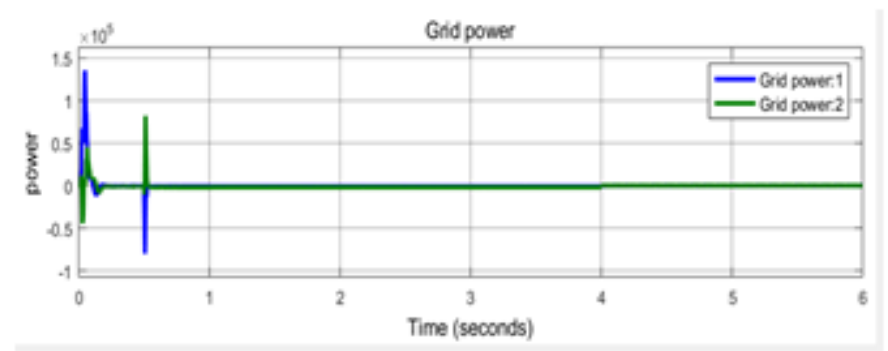

Fig. 10. Grid Power

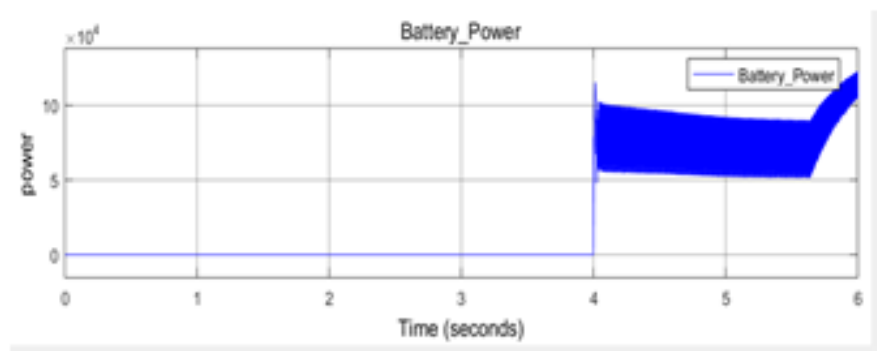

Fig. 11. Battery Power

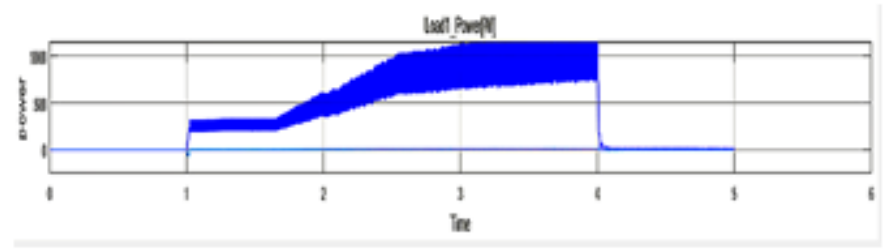

Fig. 12. Residential load 1

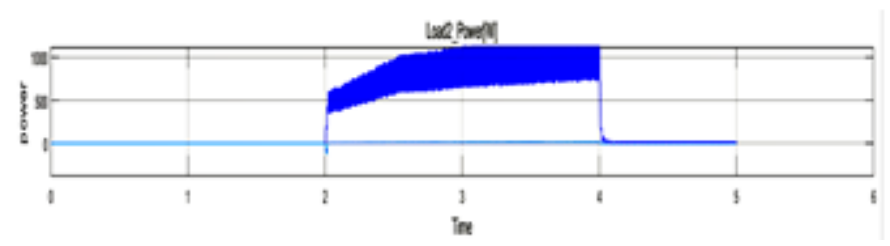

Fig. 13. Residential load2

\section{Conclusion}

Energy management system designed for Residential Grid connected microgrids designed by MATLAB/SIMULINK.contribution of residential energy management system application to the micro grid scheme in improving the system reliability is implemented by using an efficient PI controller.from the output it is observed that transient period is reduced.secondary objective is how efficiently energy management done is clearly shown in the figures with EMS and without EMS.and the third objective is maximum power point tracking which is done with MPPT algorithm.contribution of residential(EMS) to the micro grid system improve the power profile and REMS can reduce the power losses.REMS Enables power generation for local loads that makes it highly flexible and efficient. 


\section{References}

A. Mansoor, "Dc power production delivery and utiliza- tion," An EPRI White Paper, 2006.

H. Kim and M. Thottan, "A two-stage market model for microgrid power transactions via aggregators," Bell Labs Technical Journal, vol. 16, no. 3, pp. 101-107, 2011.

Q. Jiang, M. Xue, and G. Geng, "Energy management of microgrid in grid-connected and stand-alone modes," IEEE Trans. Power Syst, vol. 28, no. 3, pp. 3380-3389, 2013.

B. Jiang and Y. Fei, "Smart home in smart microgrid: A cost-effective energy ecosystem with intelligent hierarchical agents," IEEE Transactions on Smart Grid, vol. 6, no. 1, pp. 3-13, 2015.

D. Robinson and D. Edwards, "Sustainable housing design: Measurement, motivation, and management in sutherland shire, sydney, australia," Environment and Planning B: Planning and Design, vol. 36, no. 2, pp. 336-354, 2009.

M. Mikati, M. Santos, and C. Armenta, "Electric grid dependence on the configuration of a small-scale wind and solar power hybrid system," Renewable energy, vol. 57, pp. 587-593, 2013.

S. Ramakrishnan and S. Ramakrishnan, "Wot (web of things) for energy management in a smart gridconnected home," in Proceedings of the Informing Sci- ence and Information Technology Education Conference, Informing Science Institute, 2013, pp. 461-472.

N. A. Ahmed, M. Miyatake, and A. Al-Othman, "Power fluctuations suppression of stand-alone hybrid generation combining solar photovoltaic/wind turbine and fuel cell systems," Energy Conversion and Management, vol. 49, no. 10, pp. 2711-2719, 2008.

T. Saha, S. Kakkar, and D. K. Jha, "Fused converter topology for wind-solar hybrid systems," in Power and Energy Engineering Conference (APPEEC), 2013 IEEE PES Asia-Pacific, IEEE, 2013, pp. 1-7.

S. Chowdhury, S. Chowdhury, G. Taylor, and Y. Song, "Mathematical modelling and performance evaluation of a stand-alone polycrystalline pv plant with mppt facility," in Power and Energy Society General Meeting-

P N Sidhartha, S. Muthubalaji, G Devadas (2019) ." Fuzzy Pi Controller Based Single Phase Hybrid Inverter for Domestic Applications" International Journal of Engineering and Advanced Technology (IJEAT) ISSN: 2249 - 8958, Volume-9 Issue-1, PP 37-42

Conversion and Delivery of Electrical Energy in the 21st Century, 2008 IEEE, IEEE, 2008, pp. 1-7.

J.-H. Jung and S. Ahmed, "Model construction of single crystalline photovoltaic panels for real-time simulation," in Energy Conversion Congress and Exposition (ECCE), 2010 IEEE, IEEE, 2010, pp. 342-349.

S. Nema, R. Nema, and G. Agnihotri, "Matlab/simulink based study of photovoltaic cells/modules/array and their experimental verification," International journal of Energy and Environment, vol. 1, no. 3, pp. 487-500, 2010 